\title{
Development of patient-centric linguistically tailored psychoeducational messages to support nutrition and medication self-management in type 2 diabetes: a feasibility study
}

\author{
This article was published in the following Dove Press journal: \\ Patient Preference and Adherence \\ 7 October 2014 \\ Number of times this article has been viewed
}

Rebecca J Bartlett Ellis'

Ulla Connor ${ }^{2}$

James Marshall ${ }^{2}$

'Indiana University School of Nursing, ${ }^{2}$ Indiana University School of Liberal Arts, International Center for Intercultural Communication, Indiana University, Indianapolis, IN, USA
Correspondence: Rebecca J Bartlett Ellis Indiana University School of Nursing

I I I Middle Drive, E423

Indianapolis, IN 46202, USA

$\mathrm{Tel}+\mathrm{I} 3172740047$

Fax + I 3172742411

Email rjbartle@iu.edu
Purpose: This study evaluated the feasibility of developing linguistically tailored educational messages designed to match the linguistic styles of patients segmented into types with the Descriptor ${ }^{\mathrm{TM}}$, and to determine patient preferences for tailored or standard messages based on their segments.

Patients and methods: Twenty patients with type 2 diabetes (T2DM) were recruited from a diabetes health clinic. Participants were segmented using the Descriptor ${ }^{\mathrm{TM}}$, a language-based questionnaire, to identify patient types based on their control orientation (internal/external), agency (high/low), and affect (positive/negative), which are well studied constructs related to T2DM self-management. Two of the seven self-care behaviors described by the American Association of Diabetes Educators (healthy eating and taking medication) were used to develop standard messages and then linguistically tailored using features of the six different construct segment types of the Descriptor ${ }^{\mathrm{TM}}$. A subset of seven participants each provided feedback on their preference for standard or linguistically tailored messages; 12 comparisons between standard and tailored messages were made.

Results: Overall, the tailored messages were preferred to the standard messages. When the messages were matched to specific construct segment types, the tailored messages were preferred over the standard messages, although this was not statistically significant.

Conclusion: Linguistically tailoring messages based on construct segments is feasible. Furthermore, tailored messages were more often preferred over standard messages. This study provides some preliminary evidence for tailoring messages based on the linguistic features of control orientation, agency, and affect. The messages developed in this study should be tested in a larger more representative sample. The present study did not explore whether tailored messages were better understood. This research will serve as preliminary evidence to develop future studies with the ultimate goal to design intervention studies to investigate if linguistically tailoring communication within the context of patient education influences patient knowledge, motivation, and activation toward making healthy behavior changes in T2DM self-management.

Keywords: health communication, applied linguistics, patient preference, medication management, chronic disease

\section{Introduction}

Chronic disease self-management (CDSM) including self-management of type 2 diabetes (T2DM) is complex. The American Association of Diabetes Educators (AADE) recommend seven behaviors for diabetes self-management that require individuals to incorporate changes into their daily routine. These include healthy eating, regular activity, diabetes self-monitoring of blood glucose, taking medication, 
problem solving, reducing risky behaviors, and effective coping. ${ }^{1,2}$ Diabetes is associated with anxiety, ${ }^{3}$ depression, ${ }^{4,5}$ and distress. ${ }^{6}$ Self-management regimen complexity can further increase diabetes distress. ${ }^{7}$ Developing ways to help patients incorporate diabetes self-management into their daily lives while also supporting the psychosocial aspects of diabetes self-management (knowledge, skills, confidence, and emotional support) is important. ${ }^{8}$ Guidelines for medical management of diabetes indicate patients should receive both education and support. ${ }^{9}$ One of the diabetes-related Healthy People 2020 objectives is to increase the proportion of individuals who receive formal diabetes education. ${ }^{10}$ While formal diabetes education is the most effective selfmanagement educational intervention, just as critical is ongoing education and self-management support in primary care settings. ${ }^{11,12}$ Health communication strategies that increase patient attention to the important educational messages about T2DM while also attending to the psychosocial aspects of T2DM is imperative to support self-management. ${ }^{9,13}$

The core of our health care system is influenced by health information and communication. The complexity of the health care system often makes it difficult for people to understand health information. Recognizing this health information complexity, Healthy People 2020 health communication objectives are focused on providing more patient-centered and personalized communication, which includes providing "additional information, skills and supportive relationships to meet health needs." ${ }^{14}$ Health literacy or the "degree to which individuals have the capacity to obtain, process, and understand basic health information and services needed to make appropriate health decisions" $" 15$ affects people's abilities to act on health information and impacts health outcomes. ${ }^{16}$ It is estimated that over one-third to one-half of adults in the US. ${ }^{17}$ have inadequate health literacy, which is associated with poor diabetes control, ${ }^{18,19}$ medication nonadherence, ${ }^{20}$ and increased hospitalizations. ${ }^{21}$ Those at greatest risk for poor health outcomes related to health literacy include people who have trouble reading, older adults, people with low education and income levels, and those with poor health. ${ }^{22}$

Health literacy includes the ability to comprehend medical terms and concepts and make decisions about healthy behaviors and engagement in self-care and chronic disease management strategies. ${ }^{23}$ Health literacy includes five domains: reading, writing, numeracy, oral (speaking), and aural communication (listening comprehension). ${ }^{24}$ Much of the focus on health literacy has been on reading and numeracy; however, in the clinic setting, health information is most often exchanged through provider-patient verbal communications. Verbal exchange of information includes literacy skills in speaking and listening. Martin ${ }^{25}$ found that the oral exchange health literacy skills (speaking and listening) were more important in patient self-advocacy than reading and numeracy skills.

Aural communication is affected by the ability to actually hear the message and to attend to the message, as well as one's ability to perceive, comprehend, and understand the content of the information. Understanding spoken language depends on the listener's ability to receive the acoustic signal stimulus and their ability to process or "decode" the information through the central auditory processing nervous system. ${ }^{26,27}$ Decoding the auditory stimulus and cognitively processing the language through central auditory processing requires that individuals attend to the target stimuli - that is, their attention must be drawn to the stimulus. ${ }^{28}$

Parrot $^{29}$ proposed that linguistic tactics can be used to draw individuals' attention to messages. Selecting specific words, informed by linguistics, when communicating with people about self-management may create a psychological closeness between the message and the audience, also known as "verbal immediacy." ${ }^{30}$ Verbal immediacy facilitates the message receiver's awareness to the information contained in the message, which can increase one's attention to important information, such as education about T2DM selfmanagement contained within the message..$^{29,31}$

Increasing attention to messages should be a key strategy in health communication to promote adherence to T2DM self-management. In prior research, Connor and colleagues ${ }^{32}$ developed a linguistic coding system to analyze the actual words that people with T2DM used to describe their selfmanagement. They identified linguistic indicators in the way patients talk that include control orientation based on health locus of control, ${ }^{33,34}$ agency based on self-efficacy, ${ }^{35,36}$ and affect $^{37}$ or attitude/emotions. The linguistic features of these three well-studied constructs related to T2DM selfmanagement and adherence were subsequently applied to the development of a survey questionnaire, the Descriptor ${ }^{\mathrm{TM}}$. The questionnaire applies linguistics to categorize patients into eight different T2DM segments based on self-identification with actual words used by others representing combinations of construct segments of internal/external control orientation, high/low agency, and positive/negative affect. ${ }^{37}$

The conceptual definitions for control orientation, agency, and affect, that are the basis of the Descriptor ${ }^{\mathrm{TM}}$, are described below. Control orientation refers to the perceived amount of control a person has over T2DM-related events occurring in their life. In the context of health care, we see 
these as healthy behaviors that the patient perceives they can control. Internal and external control orientations are two ways that patients perceive their control. ${ }^{33,38}$ An internal control orientation is characterized by the perception that events are due to the patient's own behavior or the patient's own characteristics. ${ }^{38}$ An external control orientation is characterized by the perception that events are due partly to the patient's own actions but are also due as much or more to other influences..$^{38}$ The affect construct conveys how the patient perceives their outlook/consequences of their T2DM self-management. ${ }^{39}$ There are two different types of affect, positive and negative. A patient maintaining a positive outlook and expressing positive emotions characterizes a positive affect. A negative affect is characterized by an ongoing negative outlook and expressing negative emotions, such as frustration. The third construct incorporated into the Descriptor $^{\mathrm{TM}}$ is agency. Agency ${ }^{35,36}$ within the context of this study refers to one's capacity to follow through on instructions. In the context of health care, patients often receive instructions and prescriptions on how to manage their chronic illness or disease or how to take their medications and eat healthy foods, for example. There are also two types of agency, high and low. Following through on instructions with minimal or no lapses characterizes a patient as high agency. A patient with low agency is characterized by frequent, recurring lapses in following instructions.

The T2DM segments identified by the Descriptor ${ }^{\mathrm{TM}}$ permit linguistic tailoring of education messages for members of each segment. Audience segmentation is an approach to health communication that clusters individuals with similar qualities together and then allows for the development of interventions targeted to those clusters. ${ }^{40}$ In particular, by identifying individuals with common linguistically based psychosocial characteristics and then tailoring communication content to the various segment characteristics, the health communication may encourage audience attention to the relevant educational messages. ${ }^{41,42} \mathrm{~A}$ meta-analysis ${ }^{43}$ of tailored face-to-face messages across multiple patient populations suggests that using personal characteristics to tailor health messages may result in adoption of healthy behaviors. However, in the busy practice setting, identifying the psychosocial characteristics as a basis for tailoring health messages may be challenging, and there is no current standard for tailoring. ${ }^{44}$ Tailored messages and interventions are well-studied, and evidence supports tailored interventions; however, linguistically tailoring verbal messages based on these linguistically derived psychosocial constructs using the Descriptor ${ }^{\mathrm{TM}}$ is novel. By developing tailored messages that may enhance patient attention to the message and linguistic processing, there is a greater chance that patients will attend to the messages. Messages developed with the linguistic features of those segments should theoretically be preferred by individuals' in those segments because the language should be similar to their own language use patterns used to describe their T2DM self-management. Guided by this framework, the purpose of this study was to develop and test the feasibility of education messages tailored to match linguistic styles of patients segmented with the Descriptor ${ }^{\mathrm{TM}}$ and to determine patient preferences for tailored or standard messages based on their segments.

\section{Materials and methods}

This exploratory descriptive study evaluated the feasibility of using the Descriptor ${ }^{\mathrm{TM}}$ to linguistically tailor messages for people with T2DM and determine patient preferences for the education messages. This study involved 1) message construction, 2) patient segmentation with the Descriptor ${ }^{\mathrm{TM}}$, and 3) patient preferences for the messages.

\section{Setting}

Following institutional review and approval for the protection of human subjects, participants were recruited from a diabetes health clinic. The clinic is located in a suburban community in the Midwest. The clinic serves individuals from the county without health insurance and with a household income at or below $50 \%$ of the county median income, which is approximately $\$ 50,000$ (adjusted to family size). The clinic provides free and reduced cost diabetes care for patients with T2DM utilizing a care team consisting of certified diabetes educators and care staff trained to support patients' management of their T2DM. The clinic provides monthly diabetes education sessions both as group sessions and individual coaching sessions focused on glucose management and medication adherence.

\section{Instrumentation}

\section{Segmentation}

Patients' psychosocial segments were identified using the Descriptor ${ }^{\mathrm{TM}}$ (CoMac Analytics Inc., Indianapolis, IN, USA). This 16-item questionnaire was developed based on three constructs: control orientation, agency, and affect, identified through patient language. ${ }^{45}$ The Descriptor ${ }^{\mathrm{TM}}$ was developed through extensive patient interviews to isolate the specific words and language patterns used by people with T2DM. ${ }^{37}$ The interview analysis then provided the foundation for the items in the instrument. The actual language used in the 
instrument items are based on the language used by patients; thus, patients "see themselves" in the answers they choose. ${ }^{46}$ This instrument is commercially available through CoMac Analytics Inc. CoMac Analytics Inc. performed all scoring of the instrument and resulting participant segments were then shared with the investigators. Results consisted of each individual's segmentation consisting of internal/external control orientation, high/low agency, and positive/negative affect for participants. When evaluated in a sample of 37 individuals with T2DM, the Cohen's kappa value was 0.717 .

\section{Health literacy}

We anticipated that inadequate health literacy was of concern particularly in the reading/writing domains. Therefore, health literacy was assessed using a 3-item screening questionnaire to detect inadequate health literacy in the reading/ writing domains, with each item scored on 5-point Likert scale. ${ }^{47}$ These questions focus on problems with learning, confidence in filling out forms, and needing help in reading hospital materials. The question about filling out forms is the single best item in detecting inadequate or marginal literacy (reading/writing domains). ${ }^{48}$ These three questions can detect inadequate health literacy with overall performance measured using a receiver-operating characteristic plot of sensitivity versus 1 -sensitivity measured at 0.87 , $0.80,0.76$, respectively. ${ }^{47}$ Single item questionnaires are being used as good indicators of low literacy. ${ }^{49}$ These are single item questions; therefore, reliability estimates cannot be determined.

\section{Message construction}

Two of the seven self-care behaviors described by AADE (healthy eating/nutrition and taking medication) were chosen as the focus of messaging education. Because this was a feasibility study, only two of the seven self-care behaviors were selected for tailoring and initial testing. The nutrition and medication foci were selected based on health care provider feedback from the clinic where participants were recruited as the most common need for behavior change in this study population. The standard messages used in this study were developed based on educational sheets posted in the AADE resources and based on feedback from certified diabetes educators (CDEs).$^{50}$ The standard messages were reviewed by two CDEs and eight diabetes health coaches to ensure the messages would actually be used within the context of diabetes education and that they were consistent with the training materials used for new educators.
The standard messages used in this study were:

- Healthy eating/nutrition: include more vegetables so that you feel full longer. Choose raw vegetables that require more chewing.

- Medication management: be sure you are taking the medicine that the doctor prescribed in the way they you were told to take it.

Using the Descriptor ${ }^{\mathrm{TM}}$ and linguistic coding system previously reported for text analysis, ${ }^{32}$ we reframed the standard wording for the AADE messages using the key linguistic construct typologies to develop the tailored messages (see Table 1) using the previously described linguistic segments. The messages were constructed for each construct typology to incorporate the linguistic features characteristic of internal/ external control orientation, high/low agency, and positive/ negative affect, resulting in six separate tailored messages for healthy eating/nutrition and another six separate tailored messages for medication management for a total of 12 tailored messages. This was done to focus on the linguistic characteristics of each typology so the messages could be compared within patients' typologies in subsequent testing.

These construct-specific tailored messages were then reviewed by the two CDEs once again to validate that messages could be delivered in the context of T2DM education - making sure they were words and statements that the T2DM educators might actually use and that patients would be likely to understand. This validation was conducted informally through a consensus approach conducted via a phone conference call with both CDEs simultaneously.

\section{Procedure for comparing standard versus tailored messages}

The tailored and standard messages were presented to study participants via audio files embedded in a PowerPoint presentation. We chose to verbally deliver the messages because we anticipated reading/writing health literacy might be a concern and we also wanted to develop messages that could be provided by health care providers. Since all of the CDEs and educators from the diabetes clinic where participants were recruited were women, we used a female voice to record all of the messages. Two audio messages were presented on each slide, juxtaposing the standard message with the tailored message, or two tailored messages juxtaposed with each other. Patients were instructed to listen to both messages, one message at time, decide which one was more likely to influence them to change their self-management behaviors, and mark their responses corresponding to their preference on the response sheet. Three choices were provided for the participant to mark: message A, 


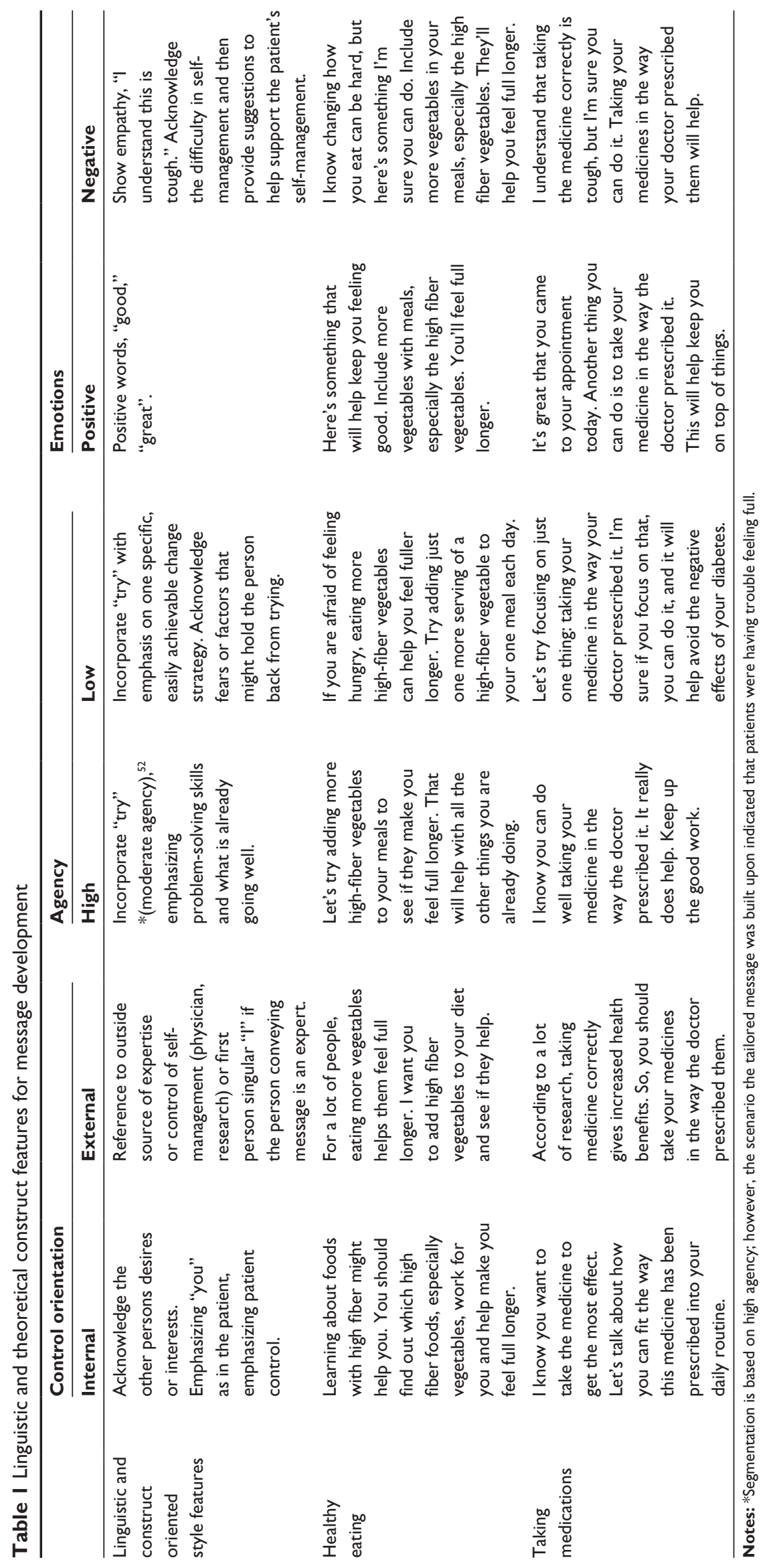


message B, or both messages would influence them equally. Participants could listen to the two messages (one at a time) on the screen multiple times and go back and forth between the two messages if needed. Participants also had the opportunity to share comments and feedback on the response form following conclusion of the message presentation.

\section{Sample}

Twenty participants with T2DM were segmented as internal/ external, high agency/low agency, and positive/negative emotion (Figure 1). Of these 20 individuals, a majority were segmented as internal control orientation, positive affect, and high agency (IPH) and external control orientation, positive affect, and high agency (EPH), indicating variation in control orientation but similarity in affect and agency. There were 4 individuals who scored equally positive and negative on the affect construct. These individuals were considered "balanced" affect - which was an unexpected finding from the Descriptor ${ }^{\mathrm{TM}}$. One individual did not respond to an affect question, making affect segmentation impossible for this individual. A subset of eight individuals was purposively selected and invited to provide feedback on their preference for educational messages tested in this study. This subset was selected to represent the eight segments based on the Descriptor ${ }^{\mathrm{TM}}$.

\section{Data analysis}

Data are summarized using descriptive statistics. Frequencies and percentages were used to summarize the preference for messages as either preference for the tailored message, preference for the standard message, or preference for both messages equally. There were two standard messages (medications and healthy eating) presented along with the tailored message for each construct typology (internal/external control orientation, high/low agency, positive/negative affect messages), resulting in 12 different tailored messages that were presented to the patients in different combinations. The denominator for calculating percentages was determined based on the number of patients participating in evaluating the messages multiplied by the total number of message comparisons (12 tailored messages juxtaposed with a standard message). Nonparametric tests were used to evaluate differences in preference, and preference for tailored, standard, or equivalent, using the chi-square statistic, where appropriate, with alpha $=0.05$.

\section{Results}

Overall, seven patients provided feedback on the tailored and standard AADE-based messages (Figure 2). Of the 20 individuals who were initially segmented with the Descriptor, eight were invited to participate in providing feedback on the messages. One of these individuals did not follow up. Overall, seven patients provided feedback on the tailored and standard AADE-based messages (Figure 2). These seven individuals also completed the three-item questionnaire to assess their health literacy. The majority $(n=5,71 \%)$ of the participants were female. Health literacy questions identified that the participants had some moderate problems in learning about their medical condition because of difficulty understanding written information $(n=5)$. Confidence in filling out medical forms was a concern for two of the participants.

\section{Message preferences}

In the cases where the 12 tailored messages were compared with the standard message and rated by the participants $(\mathrm{n}=7)$ (medication and eating combined, $\mathrm{n}=84$ messages),

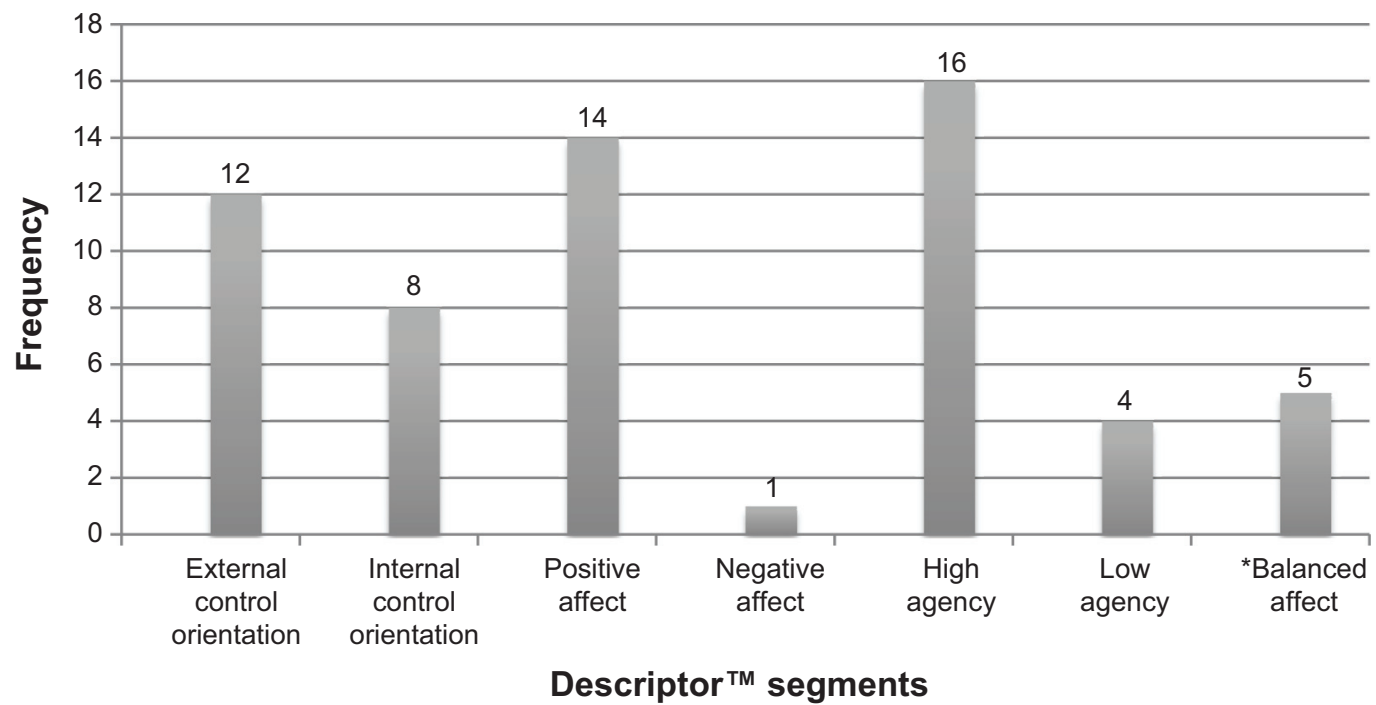

Figure I Distribution of segment clusters for all patients segmented $(n=20)$.

Note: *Balanced affect refers to individuals who scored equally on positive and negative affect $(n=4)$ on the Descriptor or who could not be segmented $(n=1)$. 


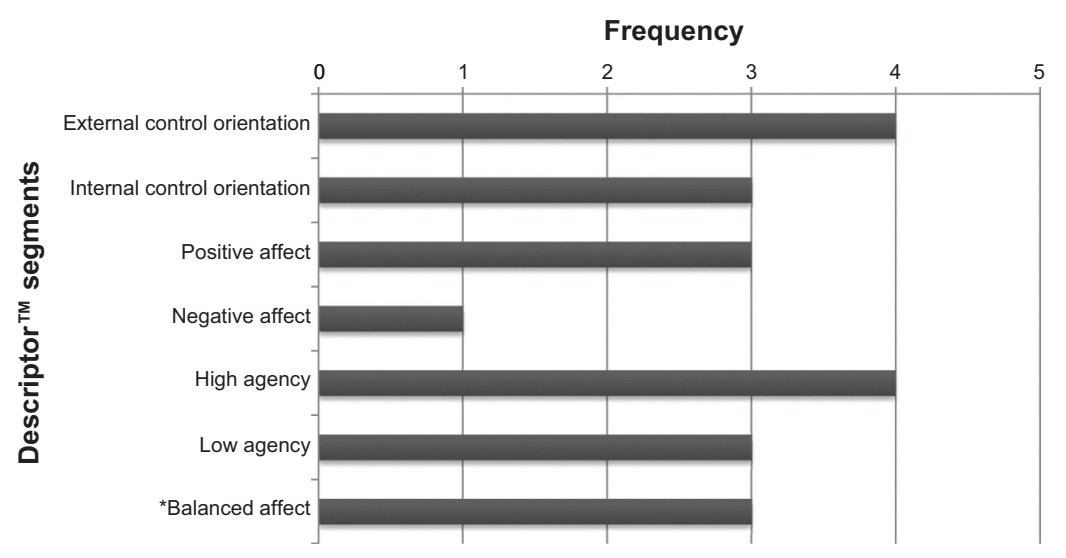

Figure 2 Study subset construct segments $(\mathrm{n}=7)$.

Note: *Balanced affect refers to individuals who scored equally on positive and negative affect items on the Descriptor. For analysis, these individuals were classified as negative affect.

regardless of the participants' segmented construct typology (internal/external control orientation, high/low agency, or positive/negative affect), approximately $65 \%(n=55)$ of the preferred messages were tailored messages; this finding was significant, $\chi^{2}(1 d f)=25.94, P<0.001$. The least preferable messages were the standard ones ( $n=13)$ (Figure 3). Counts for messages that were identified as equally preferable (tailored message equal to standard) and those where the standard message was preferred were combined $(\mathrm{n}=29)$ and compared with tailored message preference; the tailored messages were still significantly more preferred, $\chi^{2}(1 d f)=8.05, P=0.005$.

In examining the messages based on the constructs for which they were designed, there were mixed results (Figure 4), although overall, the majority of the messages designed for each construct were the messages preferred by the patients with the same typology (54.5\%). However, in $45 \%(n=25)$ of the cases, patients of the opposite construct type (eg, internal control orientation person rating an external control orientated tailored message) also preferred the tailored message compared with the standard message. The chi-square was used to evaluate if there were significant differences in preference for the tailored messages in participants whose segmented construct typology matched the message design (eg, participant with high agency preferred the high agency message versus standard message). Overall, there was no significant difference in those who preferred the messages and who also had the same typology for which the message was designed compared with those who also preferred the message but were not matched on the specific construct type, $\chi^{2}(1 d f)=1.32, P=0.251$. These results suggest high preference for the tailored messages regardless of construct segmentation.

Comparisons between those who preferred the tailored messages and the specific typology within each construct are displayed in Figure 4. Within the messages that were tailored to agency (high and low), a greater percent of the messages that were preferred by the participants also matched their segmented typology. While the participants most often times preferred the tailored messages versus the standard ones, there was not a relationship between construct typology and preference for tailored message.

\section{Discussion}

In the present study, two diabetes self-management education messages were tailored to incorporate patient's linguistic styles based on segmentation performed using the Descriptor ${ }^{\mathrm{TM}}$. Overall, the messages tailored to incorporate linguistic dimensions of control orientation, agency, and affect in the message construction are preferable to the standard messages.

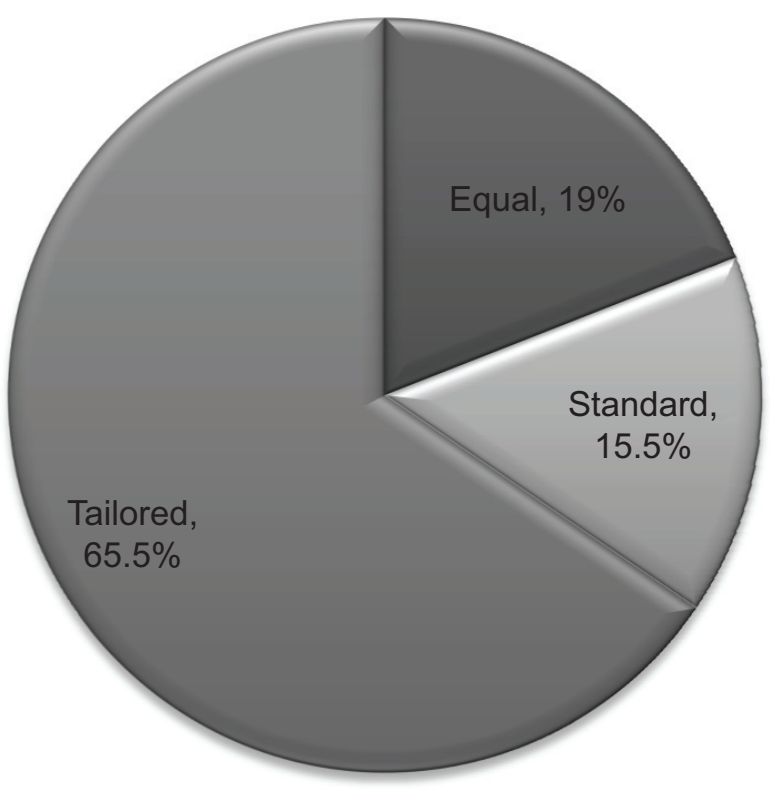

Figure 3 Diabetes' participant feedback on message preferences. 


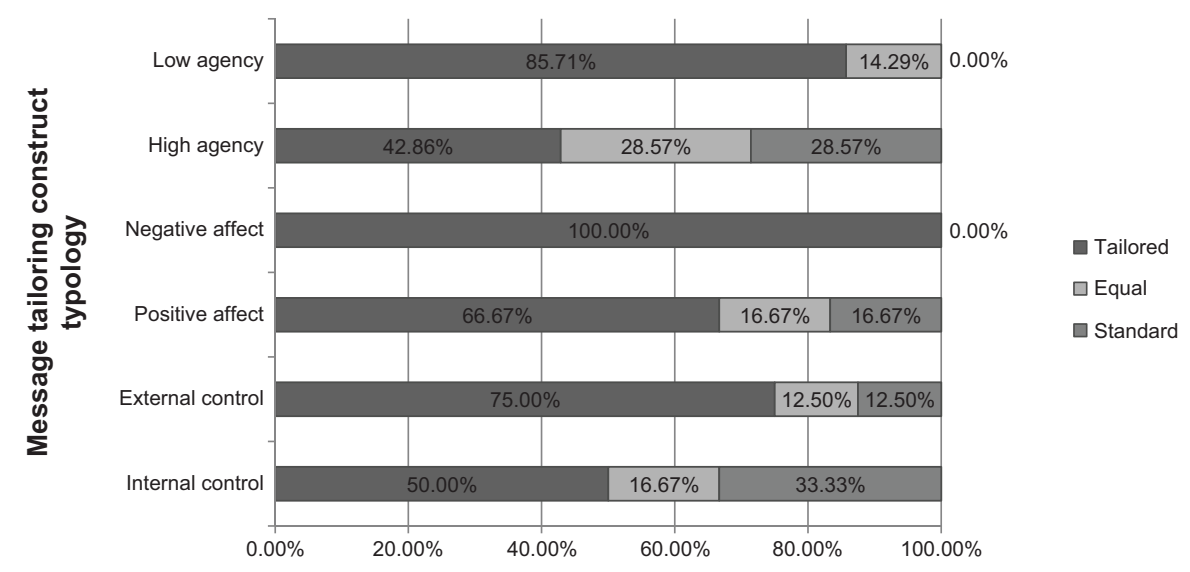

Figure 4 Participants' preferences for the messages by construct.

There was a tendency for those with the same construct typology to prefer the message tailored to their specific typology; this finding was significant. We believe that linguistic tailoring based on the individuals' construct typology accounted for the messages receiving higher preference.

By tailoring the messages to include the linguistic features of control orientation, agency, and affect, it is likely that the tailored messages were perceived as more personalized. Specifically, by adding the linguistic tailoring, participants may have perceived that the messages were more "about me" rather than the perceptions from the standard message that may have felt more like "general information." Hawkins et $\mathrm{al}^{51}$ hypothesized that tailoring leads to heuristic processing and a sense that the communicator "understands me." By further including words in message development that represent the linguistic features that have been identified, ${ }^{52}$ the message might create more verbal immediacy and thereby increase attention to the message content. Health outcomes research has identified that more pronoun use is associated with improved health outcomes. Research to date has focused on the words that people use to describe themselves, revealing an assessment of how individuals view themselves both from cognitive and emotional viewpoints $;^{53}$ however, the present study used that knowledge of patient talk to then tailor education messages for these patients, informed by their preferred linguistic styles, which we believe is a unique and innovative approach to developing health communication.

Attention to message design is important in order to maximize the benefits of education to promote selfmanagement. For example, when individuals perceive they have more personal control over their illness, they are more likely to engage in particular self-management talk and adopt more healthy behaviors. ${ }^{54}$ Linguistically tailoring to a person's agency might help increase attention to educational messages and subsequent engagement in behavior change talk and behavior change strategies needed for effective self-management of T2DM. Matching communication messages with the receiver's same linguistic style may enhance the receiver's awareness of the message and attention to the message. In natural language, there is evidence to suggest that individuals engaged in conversation will match their linguistic styles. ${ }^{55}$ However, in busy clinical practices, finding ways that can facilitate linguistic style matching early in the clinical encounter might help the health care provider to engage in more immediate relationships with the patient.

The research presents with several limitations. These are 1) that the patient's auditory status was not determined prior to research, ${ }^{14}$ 2) that the patient's literacy status was only assessed for written health literacy, 3) that message preference required multitasking attention between two messages, which may be influenced by central auditory processing status, and 4) the small sample size. Patients may have had difficulty hearing the messages, despite providing instructions to let the study moderators know if there was any difficulty hearing the messages. These limitations should be further studied in future investigations.

\section{Conclusion}

This study demonstrates that linguistic tailoring of messages is feasible and that linguistically tailored messages may be preferred over standard messages. Future research should explore preference for these same linguistically tailored messages in a larger, more representative sample, addressing the above noted limitations in this study. This was a small-scale feasibility study; therefore, generalizability is limited. This study represents the first small step in developing a program of 
research based on the application of linguistics to tailor patient communication and education to promote self-management. The present research and tailoring dimensions will serve as a foundation to build linguistically based communication interventions into psychoeducational approaches. By selecting specific linguistic features that are well attended to in educator-patient relationships, we may better engage patients in self-management; this will be investigated in well-designed psychoeducational intervention studies.

\section{Disclosure}

Ulla Connor is the chief scientific officer at CoMac Analytics, Inc., the developer and distributor of the Descriptor ${ }^{\mathrm{TM}}$ instrument used in this study. The authors have no other conflicts of interest in this work.

\section{References}

1. Amereican Association of Diabetes Educators. AADE position statement. Diabetes and physical activity. Diabetes Educ. 2012;38:129.

2. American Association of Diabetes Educators. AADE7TM Self-Care Behaviors. Chicago, IL: American Association of Diabetes Educators; 2014. Available from: http://www.diabeteseducator.org/ ProfessionalResources/AADE7/. Accessed July 23, 2014.

3. Smith KJ, Béland M, Clyde M, et al. Association of diabetes with anxiety: a systematic review and meta-analysis. JPsychosom Res. 2013; 74(2):89-99.

4. Nouwen A, Winkley K, Twisk J, et al. Type 2 diabetes mellitus as a risk factor for the onset of depression: a systematic review and metaanalysis. Diabetologia. 2010;53(12):2480-2486.

5. Roy T, Lloyd CE. Epidemiology of depression and diabetes: a systematic review. J Affect Disord. 2012;142:S8-S21.

6. Snoek FJ, Kersch NYA, Eldrup E, et al. Monitoring of Individual Needs in Diabetes (MIND): baseline data from the cross-national Diabetes Attitudes, Wishes, and Needs (DAWN) MIND study. Diabetes Care. 2011;34(3):601-603.

7. Hessler D, Fisher L, Glasgow RE, et al. Reductions in regimen distress are associated with improved management and glycemic control over time. Diabetes Care. 2014;37(3):617-624.

8. Thorpe CT, Fahey LE, Johnson H, Deshpande M, Thorpe JM, Fisher EB. Facilitating healthy coping in patients with diabetes a systematic review. Diabetes Educ. 2013;39(1):33-52.

9. American Diabetes Association. Standards of Medical Care in Diabetes, 2014. Diabetes Care. 2014;37(Suppl 1):S14-S80.

10. HealthyPeople.gov [homepage on the Internet]. 2020 Topics \& Objectives. Diabetes. US Department of Health and Human Services; 2014; Available from http://healthypeople.gov/2020/topicsobjectives2020/ objectiveslist.aspx?topicId=8. Accessed July 22, 2014.

11. Siminerio L, Ruppert KM, Gabbay RA. Who can provide diabetes self-management support in primary care? Findings from a randomized controlled trial. Diabetes Educ. 2013;39(5):705-713.

12. Norris SL, Lau J, Smith SJ, Schmid CH, Engelgau MM. Self-Management education for adults with type 2 Diabetes A meta-analysis of the effect on glycemic control. Diabetes Care. 2002;25(7):1159-1171.

13. Funnell MM, Brown TL, Childs BP, et al. National standards for diabetes self-management education. Diabetes Care. 2012;35(Suppl 1): S101-S108.

14. HealthyPeople.gov [homepage on the Internet]. 2020 Topics \& Objectives. Health Communication and Health Information Technology. US Department of Health and Human Services; 2014. Available from: http://www.healthypeople.gov/2020/topicsobjectives2020/overview. aspx?topicid=18. Accessed July 22, 2014
15. Nielsen-Bohlman L, Panzer AM, Kindig DA, editors. Health Literacy: A Prescription to End Confusion. Washington, DC: The National Academies Press; 2004.

16. Berkman ND, Sheridan SL, Donahue KE, et al. Health Literacy Interventions and Outcomes: An Updated Systematic Review. Rockville, MD: Agency for Healthcare Research and Quality (US); 2011. Available from: http://www.ncbi.nlm.nih.gov/books/NBK82434/. Accessed July 22, 2014.

17. Paasche-Orlow MK, Parker RM, Gazmararian JA, Nielsen-Bohlman LT, Rudd RR. The prevalence of limited health literacy. J Gen Intern Med. 2005;20(2):175-184.

18. Schillinger D, Grumbach K, Piette J, et al. Association of health literacy with diabetes outcomes. JAMA. 2002;288(4):475-482.

19. Williams MV, Baker DW, Parker RM, Nurss JR. Relationship of functional health literacy to patients' knowledge of their chronic disease: a study of patients with hypertension and diabetes. Arch Intern Med. 1998;158(2):166-172.

20. Zhang NJ, Terry A, McHorney CA. Impact of Health Literacy on Medication Adherence A Systematic Review and Meta-analysis. Ann Pharmacother. 2014;48(6):741-751.

21. Baker DW, Gazmararian JA, Williams MV, et al. Functional health literacy and the risk of hospital admission among Medicare managed care enrollees. Am J Public Health. 2002;92(8):1278-1283.

22. Kindig DA, Panzer AM, Nielsen-Bohlman L. Health Literacy: A Prescription to End Confusion. Washington, DC: National Academies Press; 2004.

23. Speros C. Health literacy: concept analysis. J Adv Nurs. 2005;50(6): 633-640.

24. Schonlau M, Martin L, Haas A, Derose KP, Rudd R. Patients' literacy skills: More than just reading ability. J Health Commun. 2011;16(10): 1046-1054.

25. Martin LT, Schonlau M, Haas A, et al. Patient activation and advocacy: Which literacy skills matter most? J Health Commun. 2011;16(Suppl 3): 177-190.

26. Medwetsky L. Spoken language processing: a convergent approach to conceptualizing (central) auditory processing. The ASHA Leader. Rockville, MD: American Speech-Language-Hearing Association; 2006. Available from: http://www.asha.org/publications/leader/2006/060613/ f060613a.htm. Accessed July 14, 2014.

27. American Speech-Language-Hearing Association. Central auditory processing: Current status of research and implications for clinical practice. Rockville, MD: American Speech-Language-Hearing Association; 1996. Available from: http://www.asha.org/docs/html/TR199600241.html. Accessed July 23, 2014.

28. Friederici AD. Towards a neural basis of auditory sentence processing. Trends Cogn Sci. 2002;6(2):78-84.

29. Parrott RL. Motivation to attend to health messages: presentation of content and linguistic considerations. In: Maibach E, Parrott RL, editors. Designing Health Messages: Approaches From Communication Theory and Public Health Practice. Thousand Oaks, CA: SAGE Publications, Inc.; 1995:7-24.

30. Wiener M, Mehrabian A. Language Within Language: Immediacy, a Channel in Verbal Communication. New York: Appleton-CenturyCrofts; 1968.

31. Hess AK, Gossett DAN. Nixon and the media: A study of non-immediacy in newspaper editorials as reflective of geographical attitude differences. Psychological Reports. 1974;34(3c):1055-1058.

32. Connor U, Anton M, Goering E, Lauten K, Hayat A, Balunda S. Listening to patients' voices: linguistic indicators related to diabetes self-management. Commun Med. 2012;9(1):1-12.

33. Wallston KA, Wallston BS, DeVellis R. Development of the Multidimensional Health Locus of Control (MHLC) Scales. Health Educ Monogr. 1978;6(2):160-170.

34. Rotter J. Rotter's Internal-External Locus of Control Scale. Toronto, ON: PARQol; 2011. Available from: http://www.mccc.edu/ jenningh/Courses/ documents/Rotter-locusofcontrolhandout.pdf. Accessed July 23, 2014.

35. Bandura A. Self-efficacy mechanism in human agency. American Psychologist. 1982;37(2):122. 
36. Bandura A. Human agency in social cognitive theory. Am Psychol. 1989;44(9):1175-1184.

37. Clark CM Jr, Connor U, Lauten K, Mac Neill R Jr, Sandy R. A linguistic approach to improving self-care and compliance. Journal for Patient Compliance. 2012;2(4):20-22.

38. Wallston BS, Wallston KA. Locus of control and health: a review of the literature. Health Educ Monogr. 1978;6(2):107-117.

39. Gherman A, Schnur J, Montgomery G, Sassu R, Veresiu I, David D. How are adherent people more likely to think? A meta-analysis of health beliefs and diabetes self-care. Diabetes Educ. 2011;37(3):392-408.

40. Slater MD. Choosing audience segmentation strategies and methods for health communication. In: Maibach E, Parrott RL, editors. Designing Health Messages: Approaches From Communication Theory and Public Health Practice. Thousand Oaks, CA: SAGE Publications, Inc.; 1995:186-198.

41. Maibach EW, Maxfield A, Ladin K, Slater M. Translating health psychology into effective health communication the american healthstyles audience segmentation project. J Health Psychol. 1996;1(3):261-277.

42. Slater MD. Choosing audience segmentation strategies and methods for health communication. In: Maibach EW, Parrott RL, editors. Designing Health Messages: Approaches From Communication Theory and Public Health Practice. Thousand Oaks, CA: SAGE Publications Inc.; 1995:186.

43. Wanyonyi KL, Themessl-Huber M, Humphris G, Freeman R. A systematic review and meta-analysis of face-to-face communication of tailored health messages: Implications for practice. Patient Educ Couns. 2011;85(3):348-355.

44. Baker R, Camosso-Stefinovic J, Gillies C, et al. Tailored interventions to overcome identified barriers to change: effects on professional practice and health care outcomes. Cochrane Database Syst Rev. 2010;3(3): CD005470.
45. CoMac Analytics Inc. CoMac Descriptor ${ }^{\mathrm{TM}}$. Indianapolis, IN: CoMac Analytics Inc; 2013. Available from: http://comacanalytics.com/ solutions.html. Accessed 6/11/2014.

46. CoMac Analytics Inc. Executive Summary 2014.

47. Chew LD, Bradley KA, Boyko EJ. Brief questions to identify patients with inadequate health literacy. Fam Med. 2004;36(8):588-594.

48. Chew LD, Griffin JM, Partin MR, et al. Validation of screening questions for limited health literacy in a large VA outpatient population. J Gen Intern Med. 2008;23(5):561-566.

49. Powers BJ, Trinh JV, Bosworth HB. Can this patient read and understand written health information? JAMA. 2010;304(1):76-84

50. American Association of Diabetes Educators. Diabetes Education Curriculum: Guiding Patients to Successful Self-Management. Chicago, IL: American Association of Diabetes Educators; 2009.

51. Hawkins RP, Kreuter M, Resnicow K, Fishbein M, Dijkstra A. Understanding tailoring in communicating about health. Health Educ Res. 2008;23(3):454-466.

52. Connor U, Lauten K. A multi-method analysis of diabetes patients' health beliefs and actions. In: Hamilton H, Chou WS, eds. Handbook of language and health communication. New York: Routledge; 2014.

53. Pennebaker JW, Chung CK, Ireland M, Gonzales A, Booth RJ. The Development and Psychometric Properties of LIWC2007. Austin, TX: LIWC.net; 2007.

54. Marks R, Allegrante JP, Lorig K. A review and synthesis of research evidence for self-efficacy-enhancing interventions for reducing chronic disability: implications for health education practice (part II). Health Promot Pract. 2005;6(2):148-156.

55. Niederhoffer KG, Pennebaker JW. Linguistic style matching in social interaction. J Lang Soc Psychol. 2002;21(4):337-360.
Patient Preference and Adherence

\section{Publish your work in this journal}

Patient Preference and Adherence is an international, peer-reviewed, open access journal that focuses on the growing importance of patient preference and adherence throughout the therapeutic continuum. Patient satisfaction, acceptability, quality of life, compliance, persistence and their role in developing new therapeutic modalities and compounds to optimize

\section{Dovepress}

clinical outcomes for existing disease states are major areas of interest for the journal. This journal has been accepted for indexing on PubMed Central. The manuscript management system is completely online and includes a very quick and fair peer-review system, which is all easy to use. Visit http://www. dovepress.com/testimonials.php to read real quotes from published authors. 